\title{
Antibacterial Activity of Manuka Honey Against Azithromycin Resistant Extensively Drug Resistant Salmonella Typhi Clinical Isolates: In-Vitro Study
}

Kokab Jabeen ( $\square$ kaukab-jabeen@yahoo.com )

University of Health Sciences Lahore

\section{Sidrah Saleem}

University of Health Sciences Lahore

Faiqa Arshad

University of Health Sciences Lahore

Zill-e-Huma

University of Health Sciences Lahore

Shah Jahan

University of Health Sciences Lahore

Summiya Nizamuddin

University of Health Sciences Lahore

\section{Research Article}

Keywords: Manuka honey, ESBL, XDR Typhoid, Azithromycin

Posted Date: January 13th, 2022

DOI: https://doi.org/10.21203/rs.3.rs-1144473/v1

License: (9) (i) This work is licensed under a Creative Commons Attribution 4.0 International License.

Read Full License 


\section{Abstract}

Typhoid fever is a significant health problem in developing countries like Pakistan. Salmonella Typhi the causative agent of typhoid has developed resistant to almost all recommended antibiotics. Emergence of resistance to third generation cephalosporins has further complicated the situation and such strains are called as extensively drug resistant (XDR) Salmonella Typhi. Currently only available options are azithromycin and cabapenems. Recently few reports of azithromycin resistance have emerged from countries like Pakistan, India, Bangladesh and Nepal. As azithromycin is the only oral option available to treat XDR Typhoid, development of resistance may change treatment strategy altogether from out patient management to hospitalization of every patient. This may increase the burden on already weak health care system of countries like Pakistan. So there is dire need to look for the alternative treatment options. Manuka honey is well known for its therapeutic potential against wide range of bacteria including Salmonella Typhimurium. In this study 3 azithromycin resistant isolates were isolated and identified using disc diffusion, E-test and broth micro dilution methods and antibacterial activity, MIC and MBC of manuka honey was performed by agar well diffusion assay and broth micro dilution assay respectively. Manuka honey manifested significant antibacterial activity against all test isolates with zone of inhibition ranging from $7.3 \mathrm{~mm}$ to $7.5 \mathrm{~mm}, \mathrm{MIC}$ and $\mathrm{MBC}$ values were between 10 to $15 \% \mathrm{v} / \mathrm{v}$ Here, we conclude that Manuka honey possess potent antibacterial activity and might be used as an alternative treatment option against azithromycin resistant XDR Typhid. However, further clinical trials are mandatory to validate our initial findings.

\section{Introduction:}

Extensively drug resistant Typhoid is emerging as a significant problem in developing countries like Pakistan. Since 2016, Pakistan is going through a major outbreak of this disease (Klemm et al, Rasheed et al). These XDR isolates are resistant to all recommended antibiotic leaving behind options of azithromycin as an oral and carbapenems as parenteral treatment option. Recently few reports of azithromycin resistance in Salmonella Typhi have emerged from India, Nepal, Bangladesh and Pakistan (Shoaib et al, Fida et al, Sajib et al, Iqbal et al, Pham et al, Hussain et al). World health organization has classified Salmonella Typhi as the priority pathogens against which there is dire need to look for the new treatment options. Manuka honey is known for its healing properties against wide range of multi drug resistant bacteria and viruses.

Its antibacterial activity is attributed to the presence of methylglyoxal (MGO), which, in combination with acidic $\mathrm{pH}$, high osmotic pressure, immune modulation, and the presence of trace elements, enhances its antibacterial effects (Carter et al). In-vivo, manuka honey causes extensive bacterial lysis, and it is difficult to believe that bacteria can develop resistance to its multifactorial effects. Manuka honey contains a variety of chemical compounds that may work together to overcome antimicrobial resistance. Several in vitro studies on the antibacterial properties of manuka honey against multidrug-resistant pathogens have been published (Roberts et al, Jenkins et al). In a previous study at our center, BALB/c mice were infected with methicillin-resistant Staphylococcus aureus (MRSA) and treated intravenously 
with Manuka honey. Surprisingly, all of the mice were saved with no reported deaths (Saleem S, 2013). A study conducted in our laboratory revealed that the MIC of Manuka honey was 7 percent $(\mathrm{v} / \mathrm{v})$ for both Salmonella paratyphi A and Salmonella paratyphi B, and 7 percent to 8 percent for S. typhi (Hannan et al., 2009). According to Molan's research, the MIC of Manuka honey against $\mathrm{S}$. typhimurium is $7 \%(\mathrm{v} / \mathrm{v})$ (Molan PC. 2010).

Although the therapeutic potential of manuka honey has been widely investigated against a variety of bacterial infections, no study has been conducted to date to investigate the antibacterial activity of manuka honey against XDR Salmonella Typhi clinical isolates. As a result, the purpose of this study was to determine the in vitro activity of manuka honey against azithromycin resistant XDR Typhoid clinical isolates.

\section{Study design}

This was a Cross-sectional study.

\section{Setting}

This study was conducted at The Department of Microbiology, University of Health Sciences, Lahore.

\section{Duration}

6 months (January 2021 to June 2021).

\section{Sample Collection:}

A total of 150 positive blood cultures for XDR Salmonella Typhi were collected from blood different tertiary care hospitals of Lahore. Out of 150, 3 were found to be azithromycin resistant.

\section{Bacterial identification}

The isolates were cultured and purified on Tryptic Soya agar. The blood culture bottle detected as positive was sub-cultured onto Blood agar (Oxoid, UK) and MacConkey agar (Oxoid, UK) incubated at 35-37C ${ }^{\circ}$.The isolate identification was initially performed by Gram-staining. Biochemical identification was done by using Analytical Profile Index-20 Enterobacterales system (BioMerieux, France) and VITEK2 (bioMérieux) consistent with the manufacturer's instructions. S. Typhi was confirmed by agglutination with genus and serotype-specific antisera (Salmonella poly antiserum A-I (Difco), Salmonella 0 antiserum (Difco), and Salmonella Vi antiserum (Difco) (Hussain et al., 2015).

\section{Antimicrobial Susceptibility}

Antimicrobial susceptibility testing was performed by Standard Kirby-Bauer Disk Diffusion method using cation adjusted Mueller-Hinton agar (MHA) (Oxoid UK), according to Clinical Laboratory Standards Institute (CLSI) guidelines 2021 and zones of inhibition were interpreted according to the 
breakpoints. The reference strains of $E$. coli $\operatorname{ATCC}^{\circledR} 25922$ and P. aeruginosa ATCC ${ }^{\circledR} 2785$ were used for consistency (Hussain et al., 2015).

\section{Minimum inhibitory concentration (MIC) determination}

The minimum inhibitory concentration of all the recommended antibiotics was determined by Vitek 2 (bioMérieux) fully automated system. S. Typhi that demonstrated high MICs against ceftriaxone and cefotaxime ( $>4 \mathrm{ug} / \mathrm{mL}$ ) was considered as XDR. For Azithromycin MIC was determined by E-Strip (liofilchem, Italy) method initially. A value of $\geq 32 \mathrm{ug} / \mathrm{L}$ was taken as sensitive according to CLSI 2021 criteria. The tests were done in duplicate and the MICs were recorded as the higher of the two values for each isolate. For broth micro dilution Azithromycin (AZM) dihydrate used in the study was procured from Sigma Aldrich Chemicals Pvt Ltd. Broth Micro dilution method (BMD) described by Clinical and Laboratory Standard Institute was adopted. The BMD method was carried out on sterile 96 well polystyrene round bottom micro titer plates using two-fold dilutions ranging from $0.03 \mu \mathrm{g} / \mathrm{mL}$ to 32 $\mu \mathrm{g} / \mathrm{mL}$, prepared in Cation Adjusted Mueller Hinton Broth (CAMHB) (BBL Becton, Dickinson \& Company) The test was performed in duplicates to ensure repeatability. Control wells were maintained in each row for growth control and media control (Kokare et al., 2021). The quality of every batch was assessed using the standard strains of Escherichia coli ATCC 25922 \& Klebsiella pneumoniae ATCC 700603.

\section{Interpretation of results}

A definite turbidity or button formation in the growth well was considered as positive. MIC was recorded as the lowest concentration at which the isolate was completely inhibited (absence of visible bacterial growth). The CLSI recommended MIC breakpoints for AZM (susceptible $\leq 16 \mu \mathrm{g} / \mathrm{mL}$ and resistant $\geq 32$ $\mu \mathrm{g} / \mathrm{mL}$ ) were used for results interpretation (CLSI, 2021).

\section{Agar well diffusion assay of Manuka honey}

Antibacterial activity of undiluted Manuka honey (+20UMF) was evaluated by agar well diffusion assay against azithromycin resistant isolates adopted from punch plate assay (Boorn et al., 2010). Briefly, 0.5 McFarland bacterial suspensions were inoculated on Mueller Hinton agar plate. A sterile $6 \mathrm{~mm}$ cork borer was used to make wells on each plate. Subsequently, $120 \mu \mathrm{L}$ undiluted Manuka honey was poured in each well and plates were incubated at $37^{\circ} \mathrm{C}$ overnight. Zone of inhibition $(\mathrm{mm})$ was measured by Vernier caliber. The assay was performed in duplicate (Qamar et al, 2017).

\section{Determination of MIC and minimum bactericidal concentration (MBC) of Manuka honey}

Microbroth dilution assay was used to determine the MIC (\%v/v) and MBC (\%v/v) of the manuka honey as described previously (Qamar et al, 2017). MDR S. typhi was sub-cultured onto sheep blood agar plates and incubated for 24 hours at $37^{\circ} \mathrm{C}$. Morphologically identical colonies were picked and suspended in sterile $10 \mathrm{ml}$ tryptic soya broth (TSB) and incubated for approximately 5 hours at $37^{\circ} \mathrm{C}$ to attain a fully logarithmic phase culture. The culture was adjusted to $0.5 \mathrm{McF}$ arland turbidity calculated at $540 \mathrm{~nm}$ 
using sterile TSB as a blank and a diluent with a $1 \mathrm{~cm}$ pathway. The suspension was further diluted 1:100 with double strength TSB to achieve a final concentration of $1 \times 10^{5} \mathrm{CFU} / \mathrm{mL}$. Briefly, serial dilutions of manuka honey $(5 \%, 10 \%, 15 \%, 20 \%, 25 \%, 30 \%, 35 \%, 40 \%, 45 \%$ and $50 \%)$ were prepared in sterile distilled deionized water and $100 \mu \mathrm{L}$ of each dilution was added in 96-wells, flat bottom micro titer plates (Thermo Fisher Scientific, UK). Subsequently, $100 \mu \mathrm{L}$ of bacterial suspension was added into each well. Negative control wells contained $100 \mu \mathrm{L}$ of TSB broth only while positive control wells contained TSB medium inoculated with bacteria suspension. Micro titer plate was incubated at $37^{\circ} \mathrm{C}$ overnight at shaking incubator and visually observed for the presence or absence of growth by comparing each well with negative and positive control wells. All the procedure was performed in triplicate. The MBC is defined as first dilution with no growth on agar plate. A $10 \mu \mathrm{L}$ sample was taken from the no visible growth wells of microtiter plate and was inoculated on the nutrient agar plates (Oxoid, UK) which were incubated aerobically at $37^{\circ} \mathrm{C}$ for $24 \mathrm{~h}$. Plates were examined for cell viability. Any colonies that developed were scored as bacterial growth and no bacterial growth. All the procedures repeated in duplicate (Qamar et al, 2017).

\section{Results:}

A total of three azithromycin resistant isolates were isolated from blood culture samples collected from tertiary care hospitals of Lahore. These isolates were identified on the basis of morphology, biochemical tests and serology. Further antibiotic susceptibility was performed by Standard Kirby-Bauer Disk Diffusion method using cation adjusted Mueller-Hinton agar (MHA) (Oxoid UK), according to Clinical Laboratory Standards Institute (CLSI) guidelines 2021 and zones of inhibition were interpreted according to the breakpoints. The minimum inhibitory concentration of all the recommended antibiotics was determined by Vitek 2 (bioMérieux) fully automated system. S. Typhi that demonstrated high MICs against ceftriaxone and cefotaxime $(>4 \mathrm{ug} / \mathrm{mL}$ ) was considered as XDR. For Azithromycin MIC was determined by E-Strip (liofilchem, Italy) method initially. A value of $\geq 32 \mathrm{ug} / \mathrm{L}$ was taken as sensitive according to CLSI 2021 criteria. Broth Micro dilution method (BMD) described by Clinical and Laboratory Standard Institute was adopted. Antibacterial activity of Manuka honey was determined by agar well diffusion assay. MIC and MBC were determined by broth micro dilution assay. Manuka honey showed significant anti-bacterial activity against all the three isolates. All three isolates had zone of inhibition $7.4 \pm 0.4,7.5 \pm 0.0,7.3 \pm 0.4$ $\mathrm{mm} \pm \mathrm{SD}$ respectively (Table 1$)$. MIC (\% $/ \mathrm{v})$ and $\mathrm{MBC}(\% \mathrm{v} / \mathrm{v})$ of the manuka honey against 2 isolates was $10 \% \mathrm{v} / \mathrm{v}$, while third isolate was Inhibited and killed at $15 \%$.

Table: 1 Antibacterial activity of manuka honey against azithromycin resistant clinical isolates 


\begin{tabular}{|llll|}
\hline Azithromycin resistant isolates & $\begin{array}{l}\text { Agar well diffusion } \\
(\mathrm{mm} \pm \text { SD) }\end{array}$ & $\begin{array}{l}\text { MIC } \\
(\% \mathrm{v} / \mathrm{v})\end{array}$ & $\begin{array}{l}\text { MBC } \\
(\% \mathrm{v} / \mathrm{v})\end{array}$ \\
\hline XDR1 & $7.4 \pm 0.4$ & 10 & 10 \\
\hline XDR2 & $7.5 \pm 0.0$ & 15 & 15 \\
\hline XDR3 & $7.3 \pm 0.4$ & 10 & 10 \\
\hline
\end{tabular}

\section{Discussion:}

Typhoid fever is a major public health issue in third-world countries where hygiene and sanitation standards are still deficient. The emergence and spread of XDR Salmonella Typhi has complicated matters even more. Due to the fact that azithromycin is the only oral treatment option for XDR Typhoid, emerging resistance to this drug will shift the paradigm entirely from outpatient management to hospitalization of every patient. There is an urgent need to investigate alternative therapeutic options with low resistance potential. Manuka honey has well-documented antibacterial activity against a wide range of bacterial pathogens, including multidrug resistant and extensively drug resistant pathogens.

In a recent study by (Girma et al,Tan et al) manuka honey was found to be effective against MRSA (Methicillin resistanr Staphylococcus aureus, carbapenamase producers, extended-spectrum betalactamase producer gram negative bacteria. In a study by (Lin et al) manuka honey was very effective against major gut pathogens. Very few studies reported antibacterial activity of manuka honey against typhoidal salmonellae. In a study by (Hannan et al, 2015) manuka honey was effective in-vitro against Salmonella Typhi along with other honey samples from Pakistan. Manuka honey was found to be effective in mouse typhoid as reported by (Hannan et al, 2015). Recently, studies from Ireland and the United Kingdom demonstrated that Manuka honey has an antibacterial effect with a high zone of inhibition against MDR bacteria (Sherlock et al., 2010; Boateng and Diunase, 2015). Although no data on the MIC and MBC of manuka honey against XDR Salmonella Typhi, an ESBL producer, is currently available. However, an Indian study found that the MIC and MBC of manuka honey against ESBL producing bacteria were nearly identical (Pratibha and Manita, 2015). Similarly, a UK study reported the MIC (9.5\%) and MBC (12\%) of Mnauka honey against P. aeruginosa (Henriques et al). To summarize, manuka honey exhibits promising bactericidal activity against azithromycin-resistant XDR Salmonella Typhi. As a result, using manuka honey to treat such infections may be worth trying. In the future, this research will aid in determining the antibacterial efficacy of our local honeys in vitro and in vivo in comparison to manuka honey against various pathogens, particularly gut pathogens.

\section{Conclusion}

We concluded that Manuka honey has strong inhibitory effect against the azithromycin resistant extensively drug resistant Salmonella Typhi. Therefore, it might be used as a potential treatment option against XDR Typhoid cases following the carefully designed clinical trials. 


\section{Declarations}

\section{Ethical approval}

The study was ethically approved by the "Ethical Review Board" under reference number UHS/REG19/ERC/398 from University of health sciences, Lahore, Pakistan.

\section{Consent for publication}

Not applicable.

\section{Competing interests}

The authors declare that they have no competing interests.

\section{Conflict of interest}

The authors declare no competing interests

\section{Acknowledgments}

We would like to acknowledge all the technical staff of Microbiology department, University of health sciences, Lahore for their help and assistance.

\section{Financial Support}

No funding was involved in the study.

\section{Availability of data and materials}

The datasets used and/or analyzed during the current study are not publically available because study was completely anonymous, any demographic data or identifiable information was not obtained therefore informed consent was not required for such type of study according to the local legislation. This study was conducted using the bacterial strains which were isolated for diagnostic and treatment purpose. However it is available from the corresponding author on reasonable request. Few of them already added to the manuscript as supplementary files.

\section{Authors Contribution:}

KJ \&SS conceived the study, FA \& ZH analyzed the data, SN \& SJ drafted the manuscript. All the authors read and approved the final draft.

\section{References}


1. Boateng J, Diunase KN. Comparing the Antibacterial and Functional Properties of Cameroonian and Manuka Honeys for Potential Wound Healing-Have We Come Full Cycle in Dealing with Antibiotic Resistance? Molecules. 2015 Sep 2;20(9):16068-84. doi: 10.3390/molecules200916068. PMID: 26364634; PMCID: PMC6332115.

2. Carter DA, Blair SE, Cokcetin NN et al. Therapeutic Manuka honey: no longer so alternative. Front. Microbiol. 7, 569 (2016).dealing with antibiotic resistance? Molecules, 20: 16068-16084. https://doi.org/10.3390.

3. Clinical and Laboratory Standards Institute: Performance standards for antimicrobial susceptibility testing.CLSI Supplement M100. Clinical and Laboratory Standards Institute, Wayne; 2021.

4. Fida S, Mansoor H, Saif S, Iqbal J, Khan AQ. Clinical Perspectives of Multiple and Extensively DrugResistant Typhoid; result from a tertiary care hospital from Pakistan. J Infect Dev Ctries. 2021 Apr 30;15(4):530-537. doi: 10.3855/jidc.13539. PMID: 33956653.

5. Girma A, Seo W, She RC (2019) Antibacterial activity of varying UMF-graded Manuka honeys. PLoS ONE 14(10): e0224495. https://doi.org/10.1371/journal.pone.0224495

6. Hannan A, Jabeen K, Saleem S. Effect of different doses of Manuka honey in experimentally induced mouse typhoid. Pak J Pharm Sci. 2015 May;28(3):891-902. PMID: 26004722.

7. Henriques, A., Jenkins, R., Burton, N. andCooper, R.,2011. The effect of manuka honey on the structure of Pseudomonas aeruginosa. Eur. J. clin. Microbiol.

8. Hussain A, Satti L, Hanif F, Zehra NM, Nadeem S, Bangash TM, Peter A. Typhoidal Salmonella strains in Pakistan: an impending threat of extensively drug-resistant Salmonella Typhi. Eur J Clin Microbiol Infect Dis. 2019 Nov;38(11):2145-2149. doi: 10.1007/s10096-019-03658-0. Epub 2019 Aug 3. PMID: 31377955.

9. Hussain MB, Hannan A, Akhtar N, Fayyaz GQ, Imran M, Saleem S, Qureshi IA. Evaluation of the antibacterial activity of selected Pakistani honeys against multi-drug resistant Salmonella typhi. BMC Complement Altern Med. 2015 Feb 26;15:32. doi: 10.1186/s12906-015-0549-z. PMID: 25880671; PMCID: PMC4355501. Infect. Dis., 30: 167-171. https://doi.org/10.1007/s10096-0101065-1

10. Iqbal J, Dehraj IF, Carey ME, Dyson ZA,Garrett D, Seidman JC, Kabir F, Saha S, Baker S Qamar FN. 2020. A race against time: reduced azithromycin susceptibility in Salmonella enterica serovar Typhi in Pakistan. mSphere 5:e00215-20. https://doi.org/10.1128/mSphere

11. Jenkins R, Cooper R. Improving antibiotic activity against wound pathogens with Manuka honey in vitro. PLoS ONE 7(9), e45600 (2012). Explains the synergistic effect of Manuka honey with 15 different antibiotics against methicillin-resistant Staphylococcus aureus

12. Kokare, R.S., Bari, A.K., Pereira, J.V., Patel, K. and Poojary, A., 2021. Minimum inhibitory concentration (MIC) of Ceftriaxone and Azithromycin for blood culture isolates of Salmonella enterica spp. The Journal of Infection in Developing Countries, 15(04), pp.538-543.

13. Lin, S.M.; Molan, P.C.; Cursons, R.T. The controlled in vitro susceptibility of gastrointestinal pathogens to the antibacterial e_ect of manuka honey. Eur. J. Clin. Microbiol. Infect. Dis. 2011, 30, 569- 
574.molecules200916068

14. Molan PC: The antibacterial activity of honey: 1. The nature of the antibacterial activity. 2006. Available from

http://researchcommons.waikato.ac.nz/bitstream/handle/10289/2094/antibacterial... sequence=1. Last seen, 28th June 2014.

15. Pham Thanh Duy, Sabina Dongol, Abhishek Giri, Nguyen Thi Nguyen To, Ho Ngoc Dan Thanh, Nguyen Pham Nhu Quynh, Pham Duc Trung, Guy E Thwaites, Buddha Basnyat, Stephen Baker, Maia A Rabaa, Abhilasha Karkey, The emergence of azithromycin-resistant Salmonella Typhi in Nepal, JAC-Antimicrobial Resistance, Volume 2, Issue 4, December 2020, dlaa109, https://doi.org/10.1093/jacamr/dlaa109.

16. Pratibha, S. and Manita, W., 2015. Antibacterial activity of honey against esbl producing klebsiella pneumoniae from burn wound infections. Int. J.Curr. Pharmaceut. Res., 7: 32-36.

17. Roberts A, Maddocks S, Cooper R. Manuka honey is bactericidal against Pseudomonas aeruginosa and results in differential expression of oprF and algD. Microbiology 158(Pt 12), 3005-3013 (2012).Explains the bactericidal activity of Manuka honey against Pseudomonas aeruginosa. The expression of algD increased 16-fold while oprF expression decreased tenfold followed by honey treatment.

18. Sajib MSI, Tanmoy AM, Hooda Y, Rahman H, Andrews JR, Garrett DO, Endtz HP, Saha SK, Saha S. 2021. Tracking the emergence of azithromycin resistance inmultiple genotypes of typhoidal Salmonella.mBio 12:e03481-20. https://doi.org/10.1128/mBio.03481-20.

19. Saleem S. Efficacy of honey against MRSA systemic infections in mouse model [PhD thesis]. Department of Microbiology, University of Health Sciences, Lahore, Pakistan (2013).

20. Sherlock, O., Dolan, A., Athman, R., Power, A.,Gethin, G., Cowman, S. and Humphreys, H., 2010.Comparison of the antimicrobial activity of Ulmo honey from Chile and Manuka honey against methicillin-resistant Staphylococcus aureus,Escherichia coli and Pseudomonas aeruginosa.BMC Complem. Altern. Med., 10: 1472-6882.https://doi.org/10.1186/1472-6882-10-47.

21. Shoaib M, Satti L, Hussain A, et al. (July 31, 2021) Disc Diffusion Testing of Azithromycin Against Clinical Isolates of Typhoidal Salmonellae: A Diagnostic Conundrum. Cureus 13(7): e16777. DOI 10.7759/cureus. 16777

22. Tan, H.T.; Rahman, R.A.; Gan, S.H.; Halim, A.S.; Hassan, S.A.; Sulaiman, S.A.; Singh, K.-K.B. The antibacterial properties of Malaysian tualang honey against wound and enteric microorganisms in comparison to manuka honey. BMC Complement. Altern. Med. 2009, 9, 34.

\section{Supplementary Files}

This is a list of supplementary files associated with this preprint. Click to download.

- AzithromycinMICs.xIsx 
- XDRisolates.xIsx

Page 10/10 